\title{
Article \\ Influence of the Apron Parking Stand Management Policy on Aircraft and Ground Support Equipment (GSE) Gaseous Emissions at Airports
}

\author{
Lucas Sznajderman *, Gabriel Ramírez-Díaz (1) and Carlos A. Di Bernardi \\ Grupo Transporte Aéreo (UIDET GTA-GIAI), Departamento de Aeronáutica, Facultad de Ingeniería de la \\ Universidad Nacional de La Plata, 116th Street between 47th and 48th Street, La Plata 1900, Buenos Aires, \\ Argentina; ramirezdiaz.gabriel@gmail.com (G.R.-D.); cadibern@ing.unlp.edu.ar (C.A.D.B.) \\ * Correspondence: lucas.sznajderman@ing.unlp.edu.ar; Tel.: +54-922-1504-1333
}

Citation: Sznajderman, L.;

Ramírez-Díaz, G.; Di Bernardi, C.A.

Influence of the Apron Parking Stand

Management Policy on Aircraft and

Ground Support Equipment (GSE)

Gaseous Emissions at Airports.

Aerospace 2021, 8, 87. https://

doi.org/10.3390/aerospace8030087

Academic Editor: Michael Schultz

Received: 3 February 2021

Accepted: 16 March 2021

Published: 19 March 2021

Publisher's Note: MDPI stays neutral with regard to jurisdictional claims in published maps and institutional affiliations.
Abstract: The purpose of this study is to analyze the concept of a hybrid apron with a fixed number of parking positions considering the management model influence for the average delay per aircraft and the gaseous emissions generated by aircraft and ground support equipment (GSE) altogether. The apron is studied based on two gate management models: in the first model, the aircraft are allocated in each gate due to operational factors only; in the second model, the rules of exclusive use of each gate according to the airline are included. The emissions generated by aircraft operations and that of their GSE (produced by the service and movements on the apron) are quantified and compared in the two gate management models: operation in the standard LTO cycle of the studied aircraft, GSE emissions have a similar relation with the compared gasses (NOx and CO), ranging between $1 \%$ and $3 \%$. Further, if it compares the emissions between support vehicles and aircraft taking only into account the in-out taxiway, the relation between both CO sources shows similar values to those of the previous comparison, whereas NOx emissions produced by GSE reach an approximately $20 \%$. The study considers different demand conditions obtained from the average day of the peak month of Aeroparque Jorge Newbery airport. Subsequently, through the SIMMOD PLUS software, the aircraft operations are simulated. The gates assignment and the arrival timetables are used as inputs for the GSE study due to an analytical model developed by us. Once the operational dimension is characterized and evaluated, the necessary data to quantify the gaseous emissions from the sources (Aircraft-GSE), based on the International Civil Aviation Organization (ICAO) guidelines, is obtained.

Keywords: airport emissions; gate assignment; ground support equipment

\section{Introduction}

Airports are critical nodes in the air transport system and, as such, they face several challenges, such as sustainable development infrastructures, which must provide a balanced design between the operational and environmental dimensions.

As stated in [1], the aviation industry grows within a complex network of systems. The complexity of this network results in delays produced by many sources, including weather conditions, airspace restrictions, and airport congestion. Of these three, the main cause of delay is associated with weather conditions, which are beyond the control of the industry. In this context, one of the issues to study in depth is ground congestion and its consequences, such as the associated environmental impact, which is an aspect addressed in this study.

Particularly, ground support equipment (GSE) include, among their operations, passenger transportation from terminals to aircraft and vice versa, loading and unloading of goods, aircraft energy and fuel supply, crew transportation, and any maneuver needed to 
put the aircraft in position to take off or begin rolling. In all cases, the times and procedures of land services are key to analyze possible accidents, delays, and emissions [2].

On the basis of the analysis of different studies [3,4], a variation in the percentages regarding the emissions produced by aircraft and GSE has been noted. The aforementioned studies show results obtained from the analysis of variables associated separately with each emission source; hence, the need to make a model and comprehensive analysis considering the overall functionality of the different sources according to the allocation of parking stands; that is to say, the apron management. Considering Copenhagen, Heathrow, Brisbane, and San Diego airports, according to [5], the influence of NOx emissions produced by GSE, Auxiliary Power Unit (APU), and main engines range between 5\% and 9\%, 2\% and $9 \%$, and $87 \%$ and $93 \%$ respectively, taking into account the airport as a whole.

On the other hand, ref. [5] presents an inventory of the emissions at Copenhagen Airport (CPH), detailing the general contribution of main engines, APU and GSE in the area of movements and at the apron level. If the apron subsystem is the only one under consideration, GSE produce $63 \%$ of NOx emissions, $75 \%$ of Particulate Matter (PM), and consume $24 \%$ of fuel. This shows that the apron operational mode (aircraft-GSE) and the policy of use and allocation of stands, when considered jointly, can present optimization points regarding the operational and environmental dimensions. This issue is the focus of this study, which analyses the contribution of aircraft, GSE, and overall emissions under different management models of parking stands. Carrying on with the study of [5], it is highlighted that the estimation of the inventory is based on widely accepted guidelines used in the analysis of airport systems [6]. These guidelines were adopted in the development of this study.

\section{The System and Problem}

The main variables influencing apron design are the following: the market segment (regular, non-regular, traditional, low-cost, general aviation, or loading), specific traffic patterns (hubbing or point-to-point, demand seasonality, among others), traffic profile distribution (peaks, and valleys), stand occupancy time (SOT), number of stands, aircraft type (fleet mixture), stand use policy (regular, preferential, or exclusive), and demand structure, among others.

Basing on the analyzed bibliography, it can be noted that one of the most academically studied variables is gate assignment. Such aspect has mainly been considered and optimized from the point of view of the terminal design and the operation of the aeronautic part of the system. However, the joint analysis of the operational and environmental dimensions has little development in academic background, particularly regarding aircraft and GSE.

Among other variables, that of "Total arrival movements" was established in this study. This variable corresponds to the total amount of programmed landings in the simulation and adopted the following values: $24,30,36$, and 40 , as shown on simulated demand profiles. Landings were distributed in the time window ranging from 10:00 to 13:00. Variable "Arrival time frame" was defined with a value of three in all analyzed scenarios.

\section{Methodology}

\subsection{Literature Review}

Regarding the operational dimension, there are, for instance, some studies carried out by Mirkovic and Tosic, who address the problem of apron planning and management. Ref. [7] reviews the existing capacity models, which are based on average service time, defined from the overall demand. Additionally, such models are divided into two types: the first in which all aircraft can use all stands, and the second one in which a level of complexity associated with the existing restrictions in the stand use is added according to aircraft dimensions. In both cases, the apron highest performance capability is defined as the average number of aircraft that can be tended to in $1 \mathrm{~h}$ with a steady demand (defined by the fleet mixture and user mixture.) In addition, Ref. [7] develops a model that provides 
a capacity envelope for an apron with 11 positions, in which the stand configuration (domestic and mixed) is managed and determines the capacity for different market allocations (\% of domestic flights), and the turnaround time. Ref. [8] analyses the air level of the airport through the runway system and the apron-gates complex, assuming a fully developed taxiway system. As some authors state, there are few analytical models taking into account the apron capacity. In another study, the same authors [8] pose an airport configuration with 30 stands (22 in contact and 8 remote) with four demand configurations (characterized by the light, medium and heavy aircraft percentage) depending on the type of airport under consideration (HUB, MIXed Hub or O/D), and also propose a demand cyclical behavior, which varies pursuant to the aircraft type and airport type. The results lead to the conclusion that the characteristics associated with the type of traffic and the limiting factors cannot be disregarded.

About the problem of optimization in parking stand assignment, there are several publications focused on minimizing the distance covered by the passenger in the terminal area, summarized in [9]. Following this, Ref. [10] proposes an algorithm of stand and taxiway assignment, and compares the results obtained from SIMMOD simulations. On the other hand, Ref. [11] proposes a simulation model of gate assignment to predict the operational time in congested aprons. The implementation of this type of models in real time permits a $50 \%$ reduction of ramp times. As the author states, to identify physical conflicts, the first thing to do is studying the ramp geometry and physical limitations to understand its dynamic. Physical and operational interactions and restrictions include the aircraft taxiway preventing other aircraft to do a pushback, a narrow apron or one limited in the number of entry and exit points, and long aircraft queues waiting in the ramp for the taxiway clearance. Such restrictions depend on the ramp geometry.

The importance of the apron and taxiway system is also pointed out by [12], who explains that, in the most important airports in the United States, aircraft traffic congestion takes place in the apron and surrounding areas, leading to inefficiencies in the movement area, which are then reflected in the reduction of performance time and the increase of taxiing delays. Consequently, there is an increase in the operational costs and the environmental impact due to the emissions produced by fuel combustion. In this context, Ref. [13] analyses the emissions of the Istanbul airport and identifies the taxiway and apron as the components with the most influence over emissions, besides allocating a monetary cost based on European Union (EU) data.

There are studies that have taken into account multiple variables, among which we can mention those of [14], who presents a methodology for the performance analysis, shaping and evaluation of soil use made by airports and states where the interaction between physical, operational, environmental, economic, and social variables play a key role. Physical, operational, and environmental characteristics are directly addressed in this study. Ref. [15] analyses potential problems and limitations regarding the capacity of different apron designs, with the aim of identifying a better arrangement according to the proposed cost-benefit function. Results indicate that it is possible to identify the configuration favoring the reduction of turnaround times and, therefore, the airline costs, and a second configuration which allows strong response conditions and also a higher turnaround time. Afterwards, Ref. [16] uses a model based on a "virtual cycle", which consists of two independent models, feeding each other to optimize apron configuration. Through this "virtual cycle", the groups and number of required vehicles can be determined according to the two proposed apron configurations (independent and supported stands). Following the studies that take into account the operational and environmental aspects, there appears [17], who presents a reference framework for the evaluation of airport project designs based on sustainability performance. As pointed out, environmental and operational capability can be maximized through a long-term planning guaranteeing an effective environmental management, which compensates growth by introducing infrastructure strategies from a technological and operational point of view. This problem is not insignificant, since environmental restrictions affect a huge number of airports. For instance, 
Ref. [18] indicates that, in the case of Europe, $70 \%$ of airports are affected by environmental restrictions. Among the operational problems, it highlights the possibility of answering demand conditions, and the satisfaction of such requirement, which involves taking into account factors such as capability, environmental impact, territorial competitiveness, and operational security conditions.

\subsection{Objectives of the Research}

The aim of this study is to present the results of the application of the methodology developed to quantify the emissions of aircraft on the ground and GSE according to different gate assignation policies, service time discretization and characterization of the circulation process depending on the measures made in the Jorge Newbery (SABE) Airport.

\subsection{Methodology}

This study models different scenarios characterized according to gate assignment policy and demand condition, depending on the number of operations per hour, over which gaseous emissions produced by aircraft and GSE were studied and quantified.

There are three complementary and interrelated stages in the development of this methodology (see Figure 1):

- In the first stage, SIMMOD Plus tool (called Model 1) is used to simulate operations of aircraft on the ground, particularly on the apron. SIMMOD software is a simulation program of discreet events which allows us to study the flight field dynamic, airspace routes, taxiing operations, and departure queues sequences, among other events related to the system capacity and the delay associated with it. The software allows us to quantify the delay based on the conditional operational rules included in the model, which specify the actions to be carried out by the simulation based on the system state.

- In this study, delay is measured in minutes and defined as "the time necessary to meet the requirements of a second aircraft when, at the same time, two aircraft request the same service".

- $\quad$ The second stage corresponds to the implementation of Model 2, aiming at the study and quantification of GSE emissions produced by apron circulation and service. To do this, the covered distances are estimated through the assignment of gates. Aircraft service stage times are discretized, and other factors associated with GSE operations are identified, such as power, loading, damages, and emission factors.

- $\quad$ Finally, the third stage follows the guidelines provided by [6] and widely applied for the study of the polluting input, as observed in $[5,19]$ with the purpose of obtaining aircraft emissions.

As observed in the methodological diagram, from the output of Model 1 produced by the 20 iterations made in each scenario, characteristic mean values and standard deviation of taxiway times and delays for the analysis conditions are produced. From the total amount of iterations, one representative of mean values was selected to identify the used stand assignment sequence.

Arrivals, aircraft, and gate assignments are the outgoing data of Model 1 and the entrance to the following one (Model 2), whose objective is quantifying emissions produced by the operation of GSE vehicles apron circulation and service. Both situations are analyzed in parallel to provide the corresponding values to the proposed equation for each case revised by the authors. Values also depend on aircraft support policies determined by the types of flight (point-to-point, with scale or low cost) and the type of service associated with parking stands (use of passenger boarding bridge or remote stands).

On the other hand, Model 3 uses taxiway average and delay aircraft times produced in the arrival and departure stage and provided by Model 1 as input, since they allow us to estimate $\mathrm{CO}$ and NOx emissions.

Hereafter, it presents the measuring models and the characteristics of each of the stages above mentioned. 


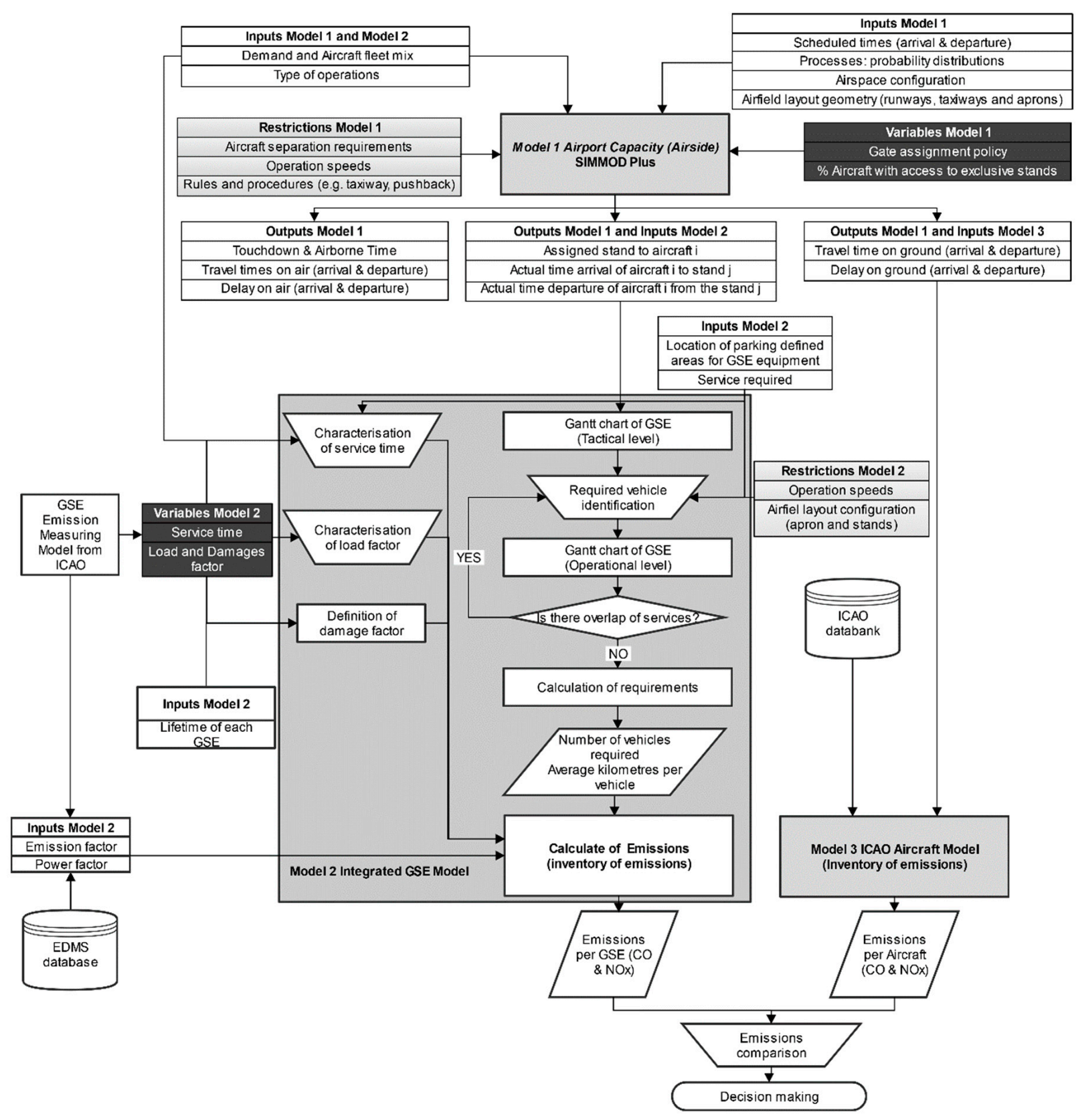

Figure 1. General methodology diagram.

\subsubsection{Assumptions}

- Distance between aircraft on the ground: $100 \mathrm{~m}$

- Taxiing speed in parallel taxiway (Alfa): $20 \mathrm{~km} / \mathrm{h}$

- Taxiing speed in apron taxiway (Bravo, Charlie, Delta, Eco, Foxtrot): $10 \mathrm{~km} / \mathrm{h}$

- Stand access speed: $5 \mathrm{~km} / \mathrm{h}$

- Pushback speed: $4 \mathrm{~km} / \mathrm{h}$

- Unique handling service provider

- Same manufacturing year for every unit of each GSE

- Equal type of fuel: diesel for each GSE

- Operation speed on ramp of $20 \mathrm{~km} / \mathrm{h}$ 


\subsubsection{Basic Structure}

Model 1-Simulation Tool

Infrastructure details

The modelled infrastructure consists of a configuration of a simple runway with a taxiway system adequately developed for the runway system. On the other hand, since the main object of study lays upon the apron complex-parking stands, this is presented including three contact points with the taxiway system (see Figures 2 and 3).

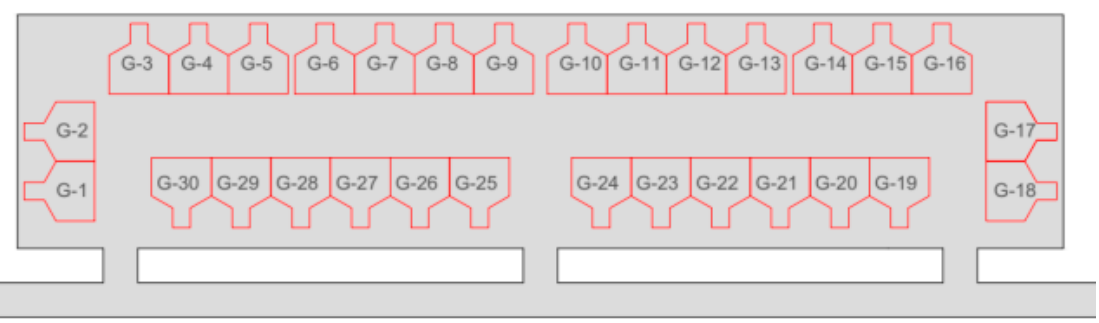

Figure 2. Parking stand assignment diagram.

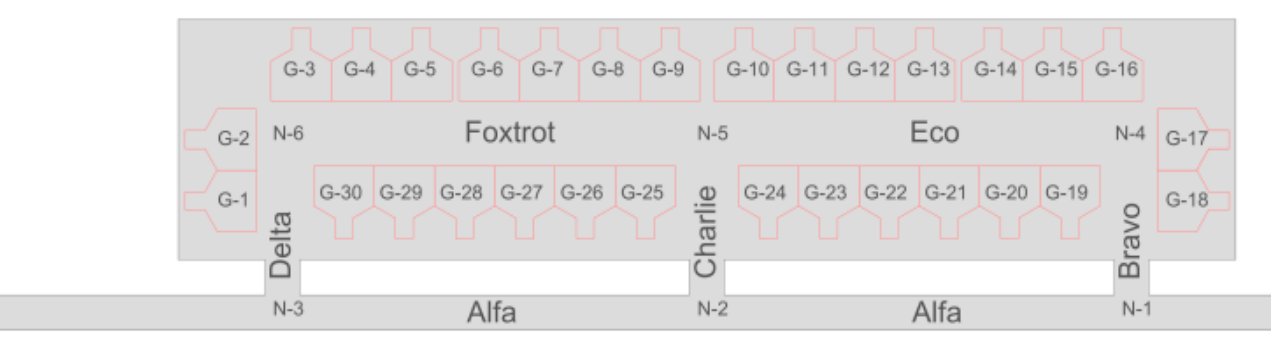

Figure 3. Taxiway allocation.

The taxiway on the apron has positions on both sides, giving rise to a hybrid configuration. The infrastructure has been shaped and characterized with $30 \mathrm{C}$-type stands. Following the ICAO classification standards, stands G-3 to G-12 are those in contact with independence entrance and supported departure maneuvers for pushback, while the remaining positions are operated with an independent entrance and departure maneuver.

The delay is calculated as the difference between the entry time and the exit time of the queue for every process the aircraft carries out.

The construction of the model involves the definition of taxiing rules in the apron entry and exit. For instance, nodes N1 to N6 are specified for the decision-making process. In node $\mathrm{N} 1$, it evaluates if the primary taxiway corresponding to that gate is conflict-free. If it is, the taxiway is the next step; if it is not, conflict resolution rules are applied on the intersections. Some conflict resolution rules are exemplified in the Appendix A.

\section{Model 2-Integrated GSE Model}

Measurement consists of two stages: the first one studies vehicle circulation on the apron and the second one consists of the sum of the polluting input due to service time discretization according to GSE equipment waiting time, connection, service (task completion) and disconnection.

From the "sophisticated" model for emission measurement provided by the ICAO, which considers five factors, power, damages, loading and operational time factors were adjusted to strengthen the model and include GSE circulation (a process that was not considered in the base model) and represent in a more precise way the special features of the operations according to the GSE service.

Next, the adapted model corresponding to the emissions produced by GSE service is presented, in which discretization of loading and time factors according to the period 
(wait, connection, service, and disconnection) for both aircraft unloading and loading are proposed.

$$
E_{i, l}=P_{i} \cdot F E_{i, l} \cdot f_{d_{1}} \cdot \sum_{j=1}^{8}\left(f \cdot c_{j} \cdot t_{j}\right)_{i}
$$
sented:

Likewise, the standardized calculation of emissions produced by circulation is pre-

$$
\mathrm{E}_{\mathrm{i}, \mathrm{l}}=\mathrm{P}_{\mathrm{i}} \cdot \mathrm{FE}_{\mathrm{i}, 1} \cdot \mathrm{f}_{\mathrm{C}_{1}} \cdot \mathrm{f}_{\mathrm{d} l} \cdot \frac{1}{\mathrm{~V}_{\mathrm{l}}} \cdot \mathrm{d}_{1}
$$

Model 3-Aircraft Emission

Measurement of aircraft and GSE emissions is based on the method proposed by [6]. Emission factors associated with the operational mode of the aircraft are obtained from [20] database.

The standardized calculation for aircraft emissions is given by

$$
E_{i, l}=\sum\left(\mathrm{TIM}_{\mathrm{jk}} \cdot 60\right) \cdot \mathrm{FF}_{\mathrm{jk}} \cdot \mathrm{Fi}_{\mathrm{ijk}} \cdot \mathrm{Ne}_{\mathrm{j}}
$$

In this study, TIM refers to the taxiway time and delays produced in the apron complex and its associated taxiway. Used times correspond to the average values obtained from the 20 iterations made on each scenario analyzed on Model 1.

\section{Results}

Demand description

Several different demand profiles, using SABE peak hour in 2017 as base line, were proposed. These used the IATA methodology to take real conditions from the arrival and departure scheduled time. The identified hour demand was reproduced for the previous and subsequent hours to analyze a representative time frame in a real operational scenario. Afterwards, on the base line (36 arrival movements in three hours), changes were made to generate different demand scenarios (operations/hour) and proportion scenarios of aircraft belonging to an airline with exclusive stand use.

Figure 4 shows the average profiles of arrivals and departures obtained using Model 1, resulting from the 20 iterations made on each scenario. As a result, the profile of the demand shows decimal values, since the proposed programming took into account an exact hour for each flight (entry data). However, the influence of random variables included in the model through the probability distributions presented on Appendix B result in some operation being carried out even after 13:00. The main goal of Figure 4 is to represent the level of activity and interaction between arrival and departure movements.

Regarding service times, the occupation times of the aircraft in the parking spot in the airport were registered for a particular time frame. According to the registries, the probability distribution presented on Appendix B and assigned to the flights on Model 1 was drafted. This distribution of turnaround time shows a minimal time of $50 \mathrm{~min}$ and a maximum of $150 \mathrm{~min}$. On Appendix B, it presents the cumulative frequency distribution of the process of the turnaround, pushback and arrival and departure latency. 


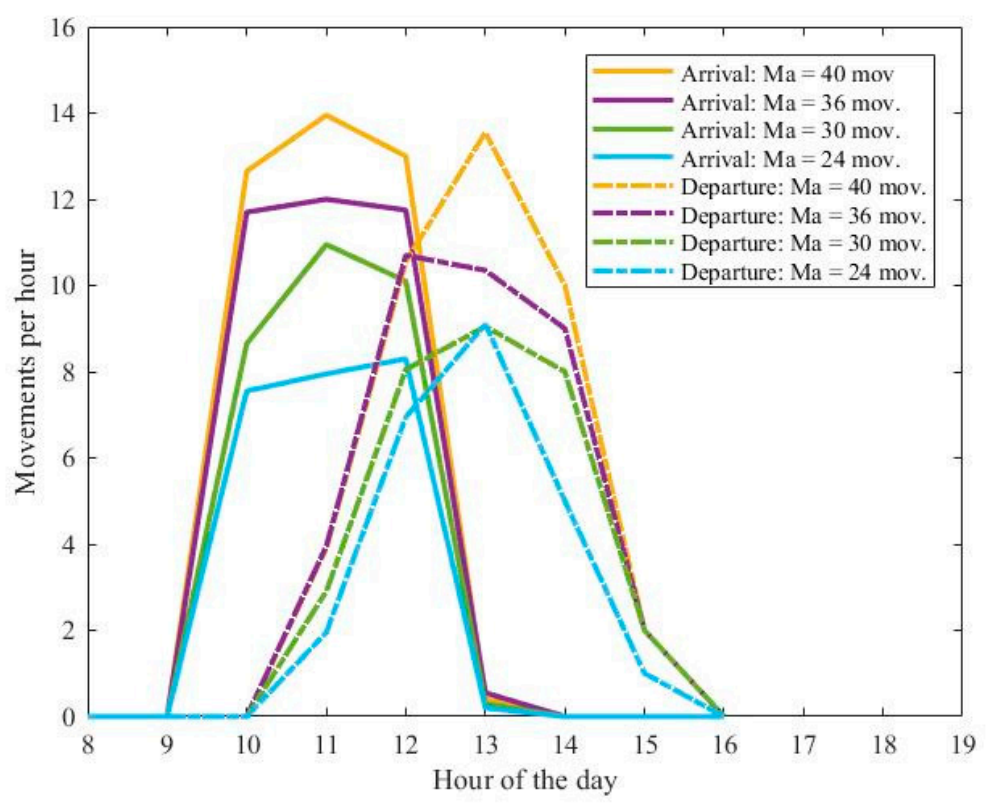

Figure 4. Simulated demand profiles.

\subsection{Description of Inputs}

Simulated scenarios

Scenarios are characterized by the parking stand assignation policy and the demand conditions which depend on the number of operations per hour.

Such policy responds to the exclusive use or not of the stand by an airline. In this study, 7 configurations of the use of stands were modelled and, on each configuration, 4 demand conditions were simulated, taking into account 3 airline participation percentages with parking stand use priority, resulting in a total of 84 scenarios subjected to 20 iterations each.

There follows a list of scenario combinations depending on the variables defining them: demand factor (DF), percentage of stands with exclusive use (\%Se), and percentage of aircraft with access to exclusive stands (\% Aircraft with priority-Aes) according to Table 1.

$$
\begin{gathered}
\mathrm{DF}=\frac{2 \cdot \mathrm{Ma}}{\mathrm{ta} \cdot \mathrm{St}} \\
\% \mathrm{Se}=\frac{\mathrm{Se}}{\mathrm{St}} \\
\% \text { Aes }=\frac{\mathrm{Aes}}{\mathrm{A}}
\end{gathered}
$$

Table 1. Variables and values assigned in the simulation.

\begin{tabular}{cc}
\hline Variables & Values \\
\hline DF & $0.40,0.65,0.80,0.88$ \\
\hline$\%$ Se & $0,6 / 30,10 / 30,15 / 30,17 / 30,20 / 30,23 / 30$ \\
\hline$\%$ Aes & $35 \%, 50 \%, 65 \%$ \\
\hline
\end{tabular}

\section{GSE Characterization}

The amount and characteristics of the support vehicles depend on the aircraft type of operation. The following possible configurations were identified: point-to point service with boarding bridge and remote stand; partial service (connecting flight) with boarding bridge and remote stand; and Low Cost (LC). 
Connecting flight is identified because, in the destination place, a full exchange of passengers, load, and fuel is produced; in a transit flight, passenger, load, and fuel exchanges take place partially and, unlike what occurs in the former case, there is no cabin or wastewater cleaning. On the other hand, on LC flights, speed, efficiency, and precision are important in the operation to minimize response times and ground handling costs. Regarding the case under study of this type of configuration, the ground power unit (GPU), catering, pushback, passenger stair, passenger bus, and cabin cleaning vehicle are not taken into account [21].

It is necessary to identify the characteristics of GSE for the traffic and service stages, which is to say, the power parameters, loading factor, emission and damage factor, traffic distances, and discretized times for the service process. In the Appendix $C$, the considered factors are presented.

Theoretical service times associated with each aircraft can be found in the corresponding Airport Planning Manual. However, the proposed emission model takes into account the characterization of the aircraft support process according to the times measured in Jorge Newbery Airport. The values have been obtained by conducting measurements for procedures during the service of the proposed GSE. "Waiting", "connection", "service" and "disconnection" are used for both unloading and loading of passengers, food, luggage, among others. As stated in Equation (1) and pointed out in Table 2, the time average is discretized for the waiting, connection, service, and disconnection.

Table 2. Average duration for GSE according to measured times in seconds.

\begin{tabular}{ccccccc}
\hline Code GSE & GSE '1' & Waiting & Connection & Service & Disconnection & Total \\
\hline BT & Baggage tractor & 92 & 20 & 531 & 13 & 547 \\
BL & Belt loader & 105 & 38 & 924 & 124 & 1191 \\
TUG & Tug & 30 & 131 & 315 & 24 & 501 \\
BUS & Bus & 53 & 0 & 292 & 0 & 332 \\
R. BUS & R. Bus & 51 & 110 & 476 & 98 & 735 \\
CAT & Catering & 134 & 102 & 376 & 109 & 721 \\
LV & Vacuum toilet & - & - & - & - & - \\
WP & Water potable & 24 & 18 & 48 & 34 & 124 \\
CLE & Cleaning & 58 & 0 & 640 & 0 & 698 \\
GPU & Ground Power Unit & 0 & 259 & 4386 & 21 & 4666 \\
PS & Passenger stairs & 68 & 54 & 298 & 0 & 419 \\
FUEL & Fuel truck & 930 & 63 & 531 & 143 & 1667 \\
\hline
\end{tabular}

Apron traffic: transfer distance

Transfer distances depend on the geometrical arrangement of the passenger terminal apron and on the location of parking defined areas for GSE equipment. Apron characterization is not only associated with geometric configuration and the identification of aircraft parking spots, but also with identification of GSE parking spots.

Airport locations have different areas intended for parking and circulation of ground support vehicles. Identifying the arrangement of these parking spots and circulation permitted zones will be of great importance since it will allow the determination of pathways associated with each of the vehicles. Said characterization will be beneficial for estimating circulation times on apron. Therefore, some considerations have to be taken into account for its measurement in apron, according to the type of procedure.

Therefore, some considerations have to be taken into account for its measurement in apron, according to the type of procedure (see Table 3). 
Table 3. Procedure type according to the parking stands of GSE vehicles.

\begin{tabular}{|c|c|c|}
\hline Type of Procedure & GSE Model & GSE Parking Stand \\
\hline A & $\begin{array}{l}\text { Conveyor } \\
\text { Freight elevators } \\
\text { Aircraft towing } \\
\text { GPU tractor } \\
\text { Passenger stair }\end{array}$ & $\begin{array}{l}\text { Each equipment staging area (ESA) } \\
\text { according to service time per } \\
\text { aircraft }{ }^{[1]} \text {. }\end{array}$ \\
\hline B & $\begin{array}{l}\text { Baggage tractor } \\
\text { Transp. PAX with reduced } \\
\text { mobility } \\
\text { Passenger transport }\end{array}$ & $\begin{array}{l}\text { Fixed parking area where } \\
\text { passengers are taken after the } \\
\text { aircraft arrival }{ }^{[2]} \text {. }\end{array}$ \\
\hline $\mathrm{C}$ & $\begin{array}{l}\text { Catering truck } \\
\text { Waste water cleaning } \\
\text { Water supply } \\
\text { Fuel tanker }\end{array}$ & $\begin{array}{l}\text { Catering, cleaning, and water } \\
\text { supplying vehicles are parked } \\
\text { outside the apron }{ }^{[3]} \text {. } \\
\text { The tanker has assigned parking } \\
\text { stands in the fuel plant on the } \\
\text { airport grounds. }\end{array}$ \\
\hline
\end{tabular}

[1] The traffic sequence in the apron depends on the availability of each group of service vehicles. ${ }^{\text {[2] }}$ It is chosen in such a way that it is best if the equipment is always moving between this point and every aircraft parking stand.

${ }^{[3]}$ Vehicles have a larger loading capacity and therefore these exit the parking stand and are able to provide a service to a higher number of aircraft.

Up next, considerations for each procedure are presented:

- Type A procedure: According to the equipment availability, a transfer between temporal GSE parking stands (ESA) can be simulated depending on the number of aircraft stands (Type $C$ as they are defined on the apron configuration) that they have to go through for the next service.

- $\quad$ Type B procedure: These vehicles always have to return to a particular operation area after providing the service to the aircraft. Therefore, it is easy to measure the transfer distance because the team goes to every aircraft parking stand and returns to its determined fixed area before moving to another aircraft.

- Type $C$ procedure: Since this equipment has a fixed parking stand, transfer distances can be estimated depending on the first arrival, along with service sequence for three extra aircraft according to the loading capacity before going back to their fixed parking stand to restock or unload wastes.

To identify the minimal amount of GSE vehicles, some Gantt diagrams have to be developed with the service time corresponding to each type of support for the amount and mixture of aircraft. The obtained service time in the corresponding Gantt diagram shows if the GSE vehicle is available or free to support another aircraft. Diagrams made for each type of service provide, as result, the minimal number of necessary vehicles for supporting aircraft in the apron on the time under study.

\subsection{Analysis of Results}

Model 1

In addition to generating assignment per gate for aircraft, the simulation performed on Model 1 obtained associated taxiway times and delays, differentiated in the arrival and departure process for each of the 84 scenarios. There were no significant variations among the scenarios on taxiway times, which is why the Figure 5 only shows the total delay (arrival and departure) produced in each scenery.

Figure 5 shows that the delay increase occurs due to the effect of three parameters on the system performance: the demand factor (DF), the percentage of stands with exclusive use (\%Se) and the percentage of aircraft with access to exclusive stands (\%Aes). Further, for the same \%Se conditions, the total delay of the system increases along with the DF rise. 


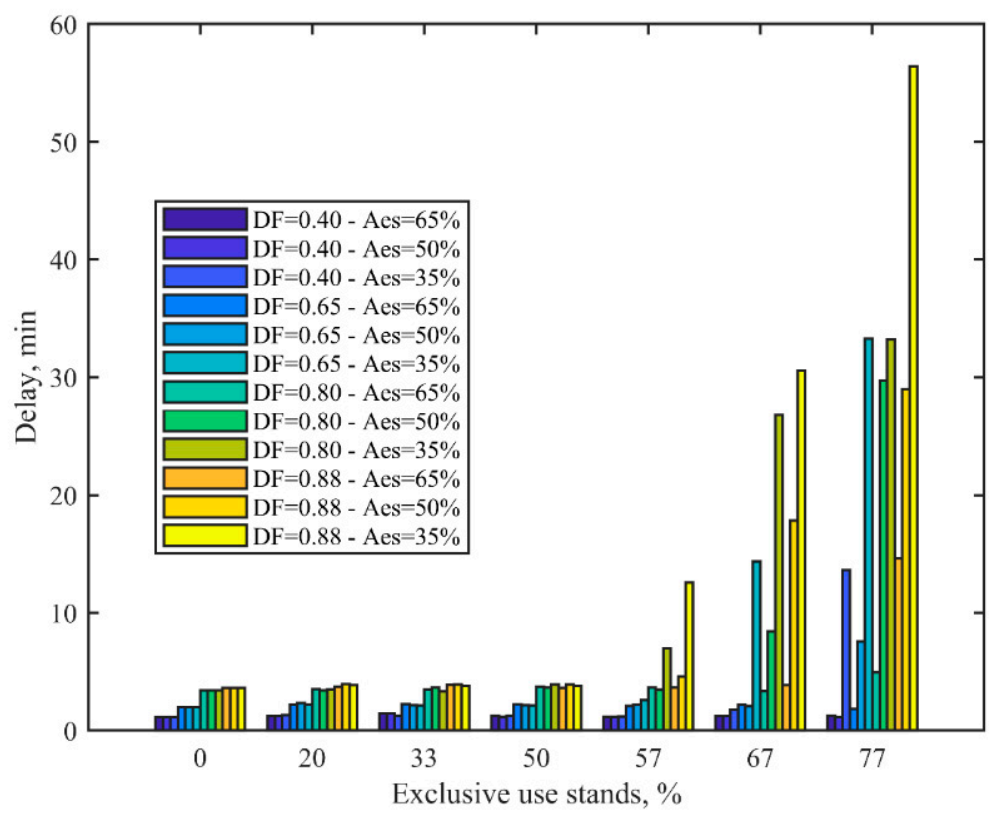

Figure 5. Delay per scenario.

Simultaneously, it is observed that for a same DF, total delay shows a behavior with two separated characteristic areas for an amount of \%Se close to $50 \%$ : the first one shows a steady behavior as \%Se increases, whereas the second one varies with the DF, in which the total delay presents a strong rise inversely proportional to \%Aes.

As a consequence, the apron complex capacity is noted depending on the demand characteristics and the infrastructure management model. Therefore, it seeks to identify the existence of an optimal point associated with the aircraft operation depending on the combination of different variables: DF, \%Aes and \%Se.

Total produced emissions may rise up to $300 \%$ due to the delay increase produced by the combination of variables that characterize the demand. In this sense, emissions increase following a behavior proportional to the relation presented hereafter, defined with the $Z$ variable.

$$
Z=\% \mathrm{Se}^{2} \cdot(1-\% \mathrm{Aes}) \cdot \mathrm{DF}
$$

Variable $Z$ is built according to the analysis of data and variables made with $R$ Studio software. The variable is presented with the objective of estimating the relationship between land delays and the characteristics of the simulation model. Equation (8) shows the adjustment, which may be considered valid with a level of confidence of 0.95 , given its p-value and T-Student and Fisher test, as observed on Figure 6, which contrasts the results obtained on the simulation with those provided by the proposed model.

$$
\text { Delay }=3.1964-67.853 . Z+622.57 . Z^{2}
$$

\section{Models 2 and 3}

With the purpose of demonstrating the effect of the gate assignment policy on emissions and the contribution of aircraft and GSE, 8 scenarios were prepared. In order to do this, variable DF is fixed with a value of 0.80 (below the congestion limit according to the reference values set forth by the Federal Aviation Administration (FAA). For variables $\%$ Aes and \%Se, the values assigned are those presented on Table 4.

Particularly, the emission produced by the processes associated with GSE service and their circulation does not show significant variations due to the gate assignment policy, while that generated by the service is constant for the same demand conditions (aircraft and type of flight). 


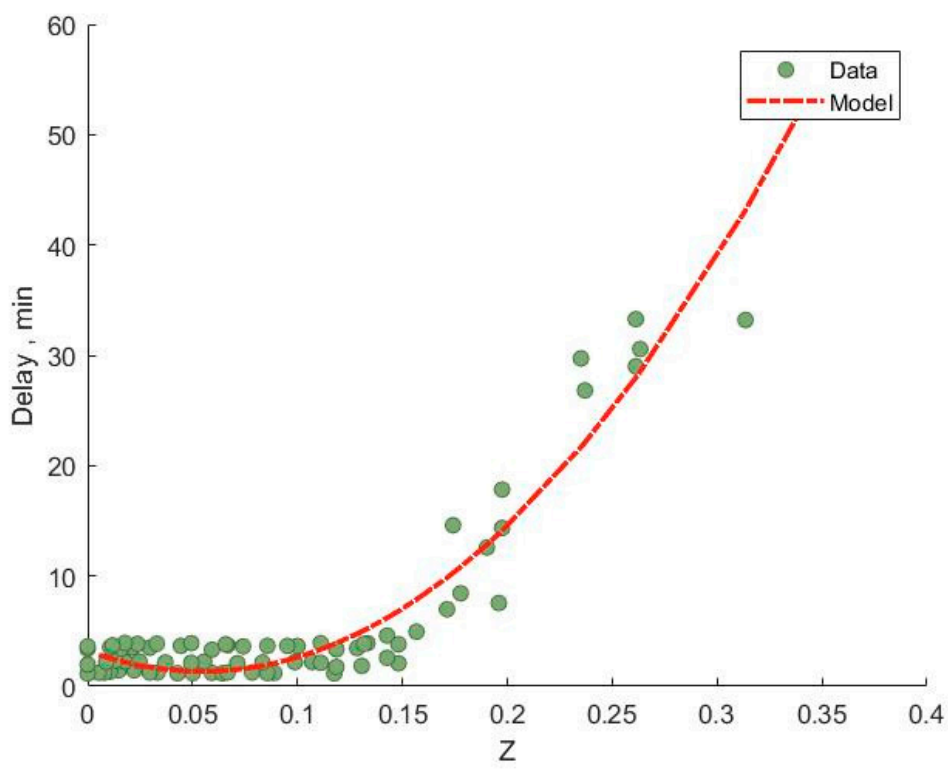

Figure 6. Simulation delay vs. adjusted model.

Table 4. Evaluated scenarios.

\begin{tabular}{ccc}
\hline Scenario & \%Aes & \%Se \\
\hline 1 & 67 & 57 \\
2 & 67 & 67 \\
3 & 50 & 57 \\
4 & 33 & 57 \\
5 & 67 & 77 \\
6 & 50 & 67 \\
7 & 50 & 77 \\
8 & 33 & 67 \\
\hline
\end{tabular}

However, if the policy of gate assignment results in aircraft operations of another scale, GSE services will logically be modified. This is because this will substantially represent a variation in the number of vehicles required, which will cause more routes in total $\mathrm{km}$, and service times will be affected. For instance, if we compare an LC flight of a narrow-body aircraft with the flight of a wide-body aircraft point to point, emissions would drastically increase. In this sense, many airports currently work proposing different measures for mitigation, such as GSE electrification, underground passages to provide services and analysis of the location of different base stations for each GSE team, to mention just a few.

Emissions produced by delays show significant variations as the gate assignment policy varies, whilst the contaminant contribution associated with aircraft movement, even though it shows variations, is insignificant compared to that produced by delays (see Table 5 and Figures 7 and 8).

Table 5. Emissions per group and process, in grams.

\begin{tabular}{lcccccccc}
\hline \multicolumn{1}{c}{ Scenario } & $\mathbf{1}$ & $\mathbf{2}$ & $\mathbf{3}$ & $\mathbf{4}$ & $\mathbf{5}$ & $\mathbf{6}$ & $\mathbf{7}$ & $\mathbf{8}$ \\
\hline CO, Travel aircraft & 58.87 & 58.16 & 54.74 & 34.82 & 31.31 & 27.71 & 18.45 & 18.48 \\
CO, Delay aircraft & 29.62 & 30.53 & 34.55 & 58.54 & 62.58 & 66.93 & 77.73 & 77.90 \\
CO, GSE per circulation & 1.29 & 1.29 & 1.21 & 0.76 & 0.70 & 0.62 & 0.44 & 0.40 \\
CO, GSE per service & 10.22 & 10.02 & 9.51 & 5.88 & 5.41 & 4.74 & 3.39 & 3.22 \\
NOx, Travel aircraft & 5.519 & 5.565 & 5.519 & 5.678 & 5.542 & 5.602 & 5.223 & 5.504 \\
NOx, Delay aircraft & 2.777 & 2.921 & 3.483 & 9.546 & 11.078 & 13.529 & 22.005 & 23.197 \\
NOx, GSE per circulation & 230 & 2.015 & 2.003 & 2.030 & 2.022 & 2.097 & 2.011 & 235 \\
NOx, GSE per service & 14.335 & 14.335 & 14.335 & 14.335 & 14.335 & 14.335 & 14.335 & 14.335 \\
\hline
\end{tabular}




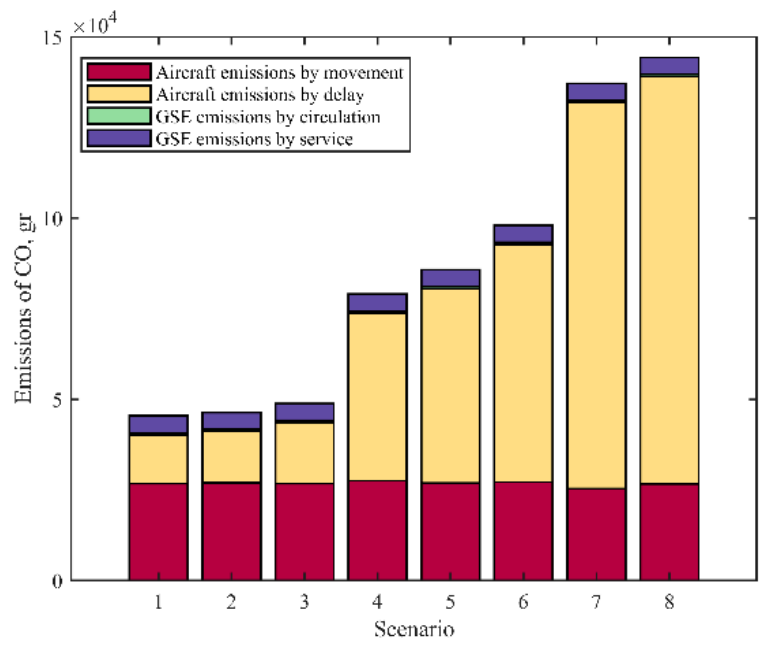

Figure 7. $\mathrm{CO}$ emissions per group and process.

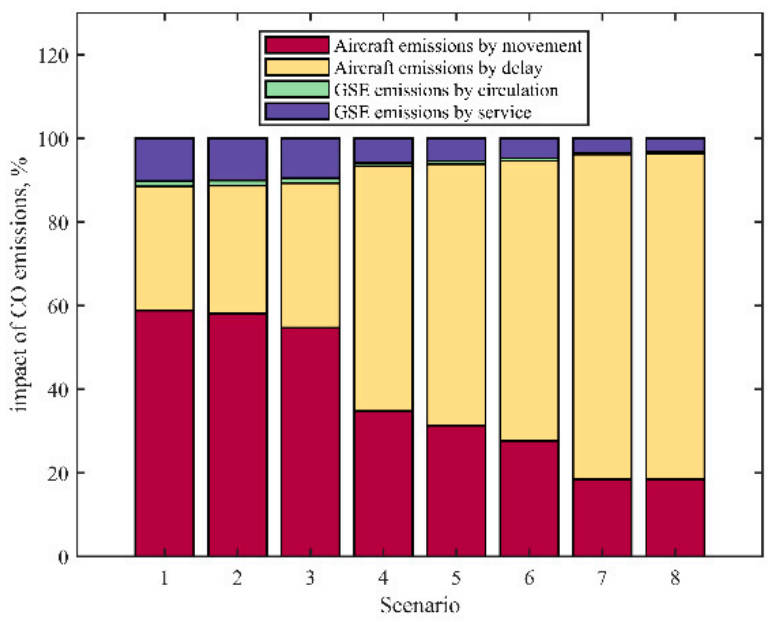

Figure 8. CO impact per group and process.

Figure 8 shows that the impact of GSE CO emissions (circulation + service) ranges between $4 \%$ and $12 \%$ according to the gate assignment policy. Whereas the impact of CO emissions from aircraft associated with the delay-movement process shows a relationship that ranges from 30-59\% (scenario 1) to 78-18\% (scenario 8) within the emission total.

Regarding NOx emissions, the performance of total emission is similar to that of CO. However, it is noted that the impact of GSE vehicles becomes more important.

Figures 9 and 10 shows that the impact of GSE NOx emissions (circulation + service) ranges between 34 and $66 \%$ according to the gate assignment policy. Whereas the impact of NOx emissions from aircraft associated with the delay-movement process shows a relationship that ranges from 12-24 (scenario 1) to 54-13\% (scenario 8) within the emission total.

As mentioned before, the service and number of GSE used in a particular airport depend mainly on the aircraft, type of flight and parking stand. Having established the variables, the corresponding emissions depend on the required vehicles. Furthermore, it is possible to obtain from Model 2 the detailed emission percentage corresponding to all GSE for a point-to-point operation, as is shown in the Figure 11: 


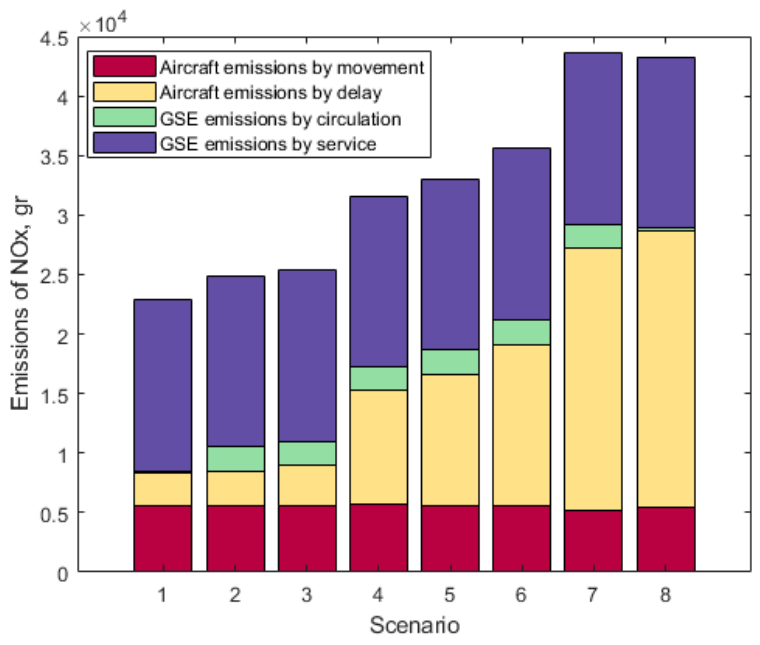

Figure 9. NOx emissions per group and process.

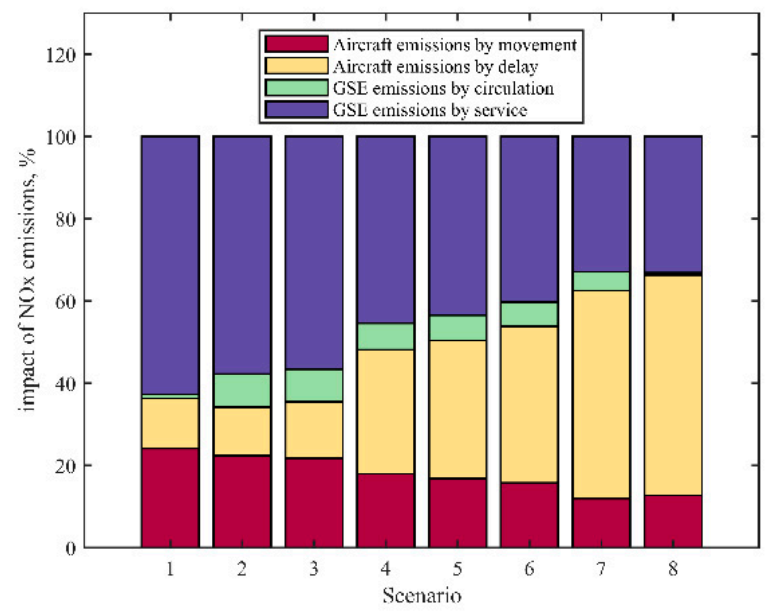

Figure 10. NOx impact per group and process.

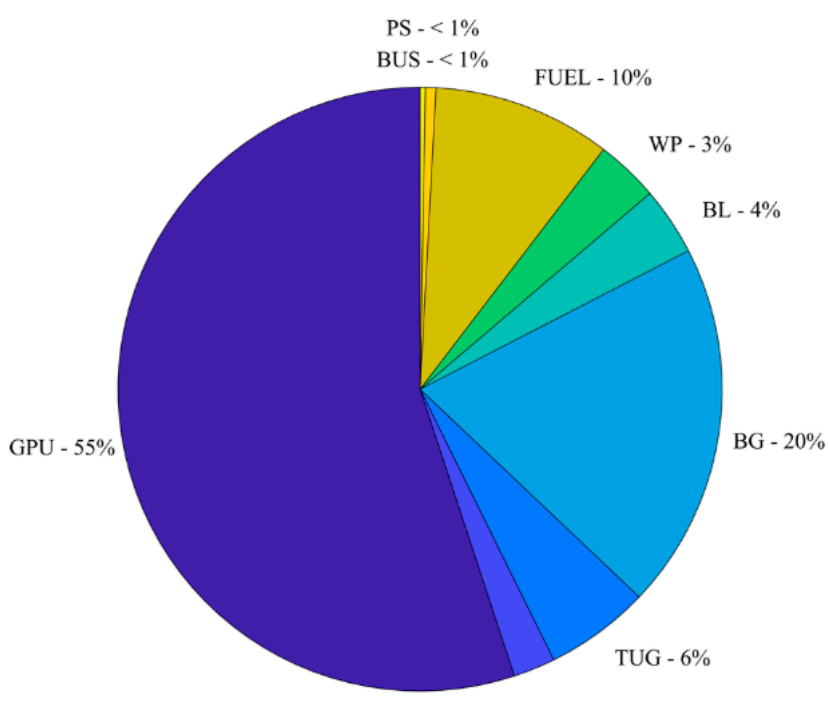

CAT - $2 \%$

(a)

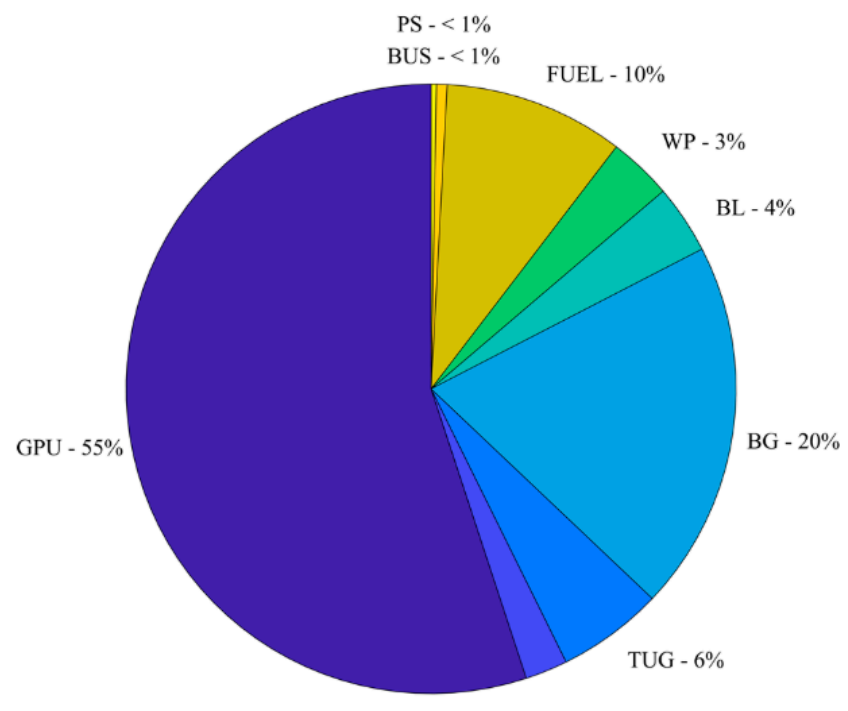

CAT $-2 \%$

(b)

Figure 11. Emissions per GSE, (a) CO, (b) NOx. 
Likewise, it is possible to compare GSE emissions during the service according to the type of flight and the parking stand using a particular aircraft. Figure 12 shows GSE emission quantification in the service provided to an A320-200:

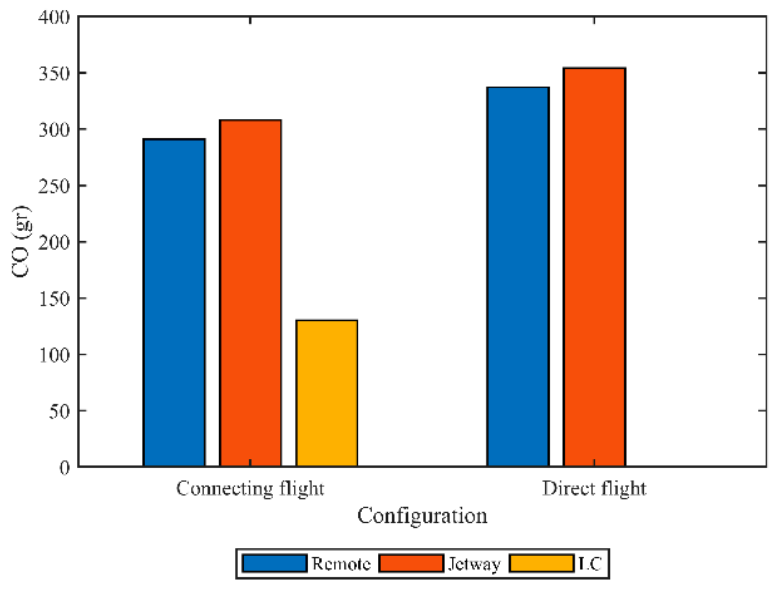

(a)

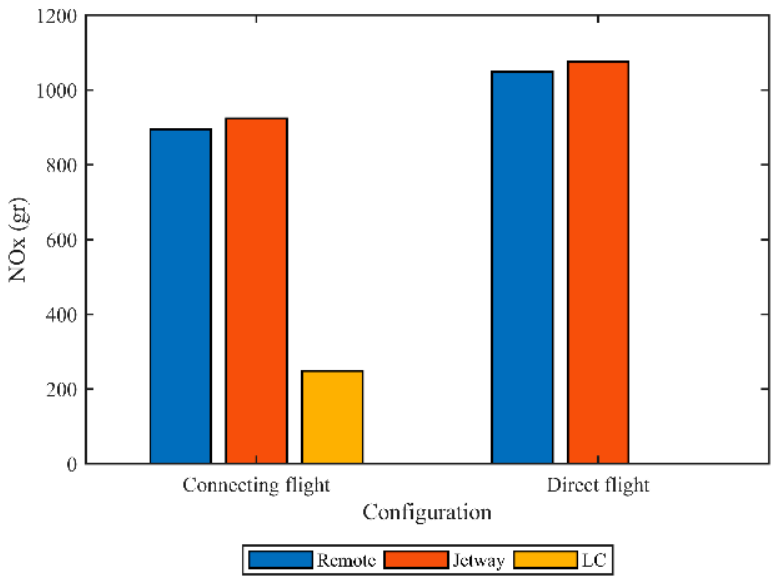

(b)

Figure 12. GSE emissions for different configurations and types of aircraft operations, (a) CO, (b) NOx.

On the other hand, each scenario and, as a consequence, each stand assignment policy brings forth a different requirement of vehicles and, therefore, of kilometers covered per vehicle. Table A3 shows that the number of vehicles varies in the scenario under analysis. However, it does not present a behavior proportional to the variables used in the characterization of the demand (\%Aes y \%Se). Furthermore, excluding the GSE associated with passenger transport, the number of vehicles required shows a stable performance with a variation range around its average value of $+/-1$ vehicle (approx. $+/-10 \%$ ). In such cases, it is noted that, given the number of travelling GSE, the inclusion of a new vehicle does not imply a significant increase in the required total (see Table 6).

Table 6. Number of vehicles required per GSE group according to modelled scenarios.

\begin{tabular}{ccccccccc}
\hline & \multicolumn{7}{c}{ Scenarios } \\
\hline GSE & $\mathbf{1}$ & $\mathbf{2}$ & $\mathbf{3}$ & $\mathbf{4}$ & $\mathbf{5}$ & $\mathbf{6}$ & $\mathbf{7}$ & $\mathbf{8}$ \\
\hline BT & 12 & 10 & 10 & 12 & 12 & 10 & 10 & 10 \\
BL & 10 & 8 & 10 & 10 & 10 & 10 & 10 & 10 \\
Bus & 10 & 8 & 10 & 12 & 10 & 10 & 14 & 10 \\
PS & 8 & 8 & 10 & 10 & 8 & 10 & 10 & 10 \\
CAT & 7 & 7 & 7 & 7 & 7 & 7 & 8 & 7 \\
LV & 5 & 5 & 5 & 5 & 5 & 5 & 5 & 5 \\
WP & 4 & 4 & 4 & 4 & 5 & 5 & 4 & 4 \\
GPU & 4 & 5 & 5 & 5 & 4 & 4 & 4 & 3 \\
Tug & 2 & 2 & 2 & 2 & 2 & 2 & 3 & 3 \\
\hline
\end{tabular}

Regarding the covered kilometers, no GSE shows a behavior directly dependent on the variables used in the demand characterization.

Table 7 shows that the variation of the required kilometers may be twice as high (see GSE case for passenger transport scenario 1 vs. scenario 8), whereas, for those which include services requiring a lower amount of GSE vehicles (GPU, and Tug), it is noted that the total amount of covered kilometers shows a higher balanced performance among scenarios. 
Table 7. Total amount of covered kilometers per vehicle.

\begin{tabular}{ccccccccc}
\hline GSE & $\mathbf{1}$ & $\mathbf{2}$ & $\mathbf{3}$ & $\mathbf{4}$ & $\mathbf{5}$ & $\mathbf{6}$ & $\mathbf{7}$ & $\mathbf{8}$ \\
\hline BT & 12.52 & 14.48 & 19.12 & 15.80 & 13.66 & 19.12 & 15.36 & 20.82 \\
BL & 11.47 & 11.58 & 8.69 & 11.74 & 13.51 & 11.86 & 12.26 & 10.49 \\
Bus & 9.64 & 13.28 & 11.68 & 15.34 & 15.62 & 18.46 & 13.09 & 20.48 \\
PS & 7.31 & 8.43 & 8.33 & 6.07 & 5.78 & 11.35 & 7.74 & 8.07 \\
CAT & 12.69 & 13.94 & 13.33 & 14.36 & 13.53 & 13.47 & 15.85 & 14.63 \\
LV & 12.43 & 11.98 & 11.82 & 11.93 & 11.31 & 12.22 & 10.90 & 12.40 \\
WP & 9.76 & 10.96 & 10.94 & 9.99 & 12.01 & 10.79 & 11.86 & 12.29 \\
GPU & 7.58 & 5.93 & 6.51 & 5.49 & 6.13 & 6.53 & 6.49 & 5.18 \\
Tug & 3.27 & 3.43 & 4.05 & 3.62 & 2.63 & 2.59 & 3.20 & 2.70 \\
\hline
\end{tabular}

If the relationship between average covered kilometers per vehicle is analyzed, it is noted that there is a significant variation between scenarios (with the exception of catering, wastewater and cleaning services). Such variation does not show a relationship between the variables used in the characterization of the demand (see Table 8):

Table 8. Average covered kilometers per vehicle.

\begin{tabular}{ccccccccc}
\hline GSE & $\mathbf{1}$ & $\mathbf{2}$ & $\mathbf{3}$ & $\mathbf{4}$ & $\mathbf{5}$ & $\mathbf{6}$ & $\mathbf{7}$ & $\mathbf{8}$ \\
\hline BT & 1.04 & 1.45 & 1.91 & 1.32 & 1.14 & 1.91 & 1.54 & 2.08 \\
BL & 1.15 & 1.45 & 0.87 & 1.17 & 1.35 & 1.19 & 1.23 & 1.05 \\
Bus & 0.96 & 1.66 & 1.17 & 1.28 & 1.56 & 1.85 & 0.93 & 2.05 \\
PS & 0.91 & 1.05 & 0.83 & 0.61 & 0.72 & 1.14 & 0.77 & 0.81 \\
CAT & 1.81 & 1.99 & 1.90 & 2.05 & 1.93 & 1.92 & 1.98 & 2.09 \\
LV & 2.49 & 2.40 & 2.36 & 2.39 & 2.26 & 2.44 & 2.18 & 2.48 \\
WP & 2.44 & 2.74 & 2.73 & 2.50 & 2.40 & 2.16 & 2.96 & 3.07 \\
GPU & 1.89 & 1.19 & 1.30 & 1.10 & 1.53 & 1.63 & 1.62 & 1.73 \\
Tug & 1.64 & 1.71 & 2.02 & 1.81 & 1.32 & 1.30 & 1.07 & 0.90 \\
\hline
\end{tabular}

Due to its particular characteristic, the fuel service appears separately due to the fact that the distance between the fuel plant and the apron varies significantly according to the airport configuration, so in this case the adopted distance was $3.2 \mathrm{~km}$ (see Table 9).

Table 9. Fuel truck, vehicle number, and kilometers covered per vehicle.

\begin{tabular}{ccc}
\hline Scenario & Number of Vehicles Required & Average Kilometers per Vehicle \\
\hline 1 & 10 & 9.3 \\
2 & 11 & 8.5 \\
3 & 11 & 8.4 \\
4 & 12 & 7.8 \\
5 & 10 & 9.3 \\
6 & 12 & 7.7 \\
7 & 10 & 9.1 \\
8 & 10 & 8.6 \\
\hline
\end{tabular}

\section{Conclusions}

The results cannot be extrapolated to all airports, but they serve a guide and reference to compare values and orders of magnitude.

In this context, the capacity of the apron complex-parking stands depends on the demand characteristics and the infrastructure management model. Therefore, the existence of an optimal point depends on the combination of different variables: DF, \%Aes, and \%Se.

Total emissions (aircraft + GSE) can increase due to the variable combination characterizing the capacity and demand, basically, because total emissions and delay are directly proportional. 
$\mathrm{CO}$ and NOx quantification associated with aircraft was classified in emissions by movement and delay. For the conditions in which the Equation (7) shows low values, the first main emission input is related to the aircraft movement, whereas, as it increases, those which prevail are the emissions originated by delay due to apron overcrowding either for conditions related to the DF (number of operations per hour) or for conditions associated with the stand assignment policy (\%Se) according to the airport operator.

Aircraft contribution to emissions has two constituents: delay and movement. Their impact shows variations according to the analyzed scenario: The delay has a CO impact ranging between $30 \%$ and $78 \%$, whereas, in movements, there is a CO impact ranging between $59 \%$ and $18 \%$. Regarding NOx, delay input ranges between $12 \%$ and $54 \%$ and movement input, between $24 \%$ and $13 \%$.

As regards GSE emissions (traffic and service) related to the total emissions (including aircraft with delay and in movement), CO impact ranges between $4 \%$ and $12 \%$ for the different scenarios; whereas those of NOx range between $34 \%$ and $66 \%$, according to the gate assignment policy. On the other hand, if only GSE operation is analyzed, the service represents $88 \%$ of CO emissions, while NOx emissions range between $88 \%$ and $98 \%$ according to the gate assignment policy. During the service, the results show that the GPU and baggage tractor emits $70 \%$ of the total adding up both on CO and NOx. This is due to the fact that the first one is the one offering the service for most time (4666 s), whereas the high emissions produced by BT are the result of high FC they have in both loading and unloading states. Moreover, in both cases it is noted that the EF is one of the highest after BL.

The point-to-point service is the one producing more emissions, followed by the service in flights with scales and finally by the one in Low Cost (LC) flights. In addition, it is noted that the services for aircraft with boarding bridges are minimally higher both in point-to-point flights and flights with scales, even though they require less vehicles.

Compared to the operation in the standard LTO cycle of the studied aircraft, GSE emissions have a similar relation with the compared gasses (NOx and $\mathrm{CO}$ ), ranging between $1 \%$ and $3 \%$. On the other hand, if it compares the emissions between support vehicles and aircraft taking only into account the in-out taxiway, the conclusion is that, on the one hand, the relation between both $\mathrm{CO}$ sources shows similar values to those of the previous comparison, whereas NOx emissions produced by GSE reach an approximately $20 \%$.

Even though time measurements were taken at Jorge Newberry Airport, the times associated to the proposed stages are similar for services with similar features. Furthermore, the methodology can be implemented in other airports with similar geometric characteristics and operations. This is so because of each GSE operation and circulation, which, in turn, depends on the service needed to be provided to the aircraft (commercial or loading flights, number of passengers, etc.).

Author Contributions: During this research, G.R.-D. worked mostly in the development of model 1 while C.A.D.B. and L.S. focused on Models 2 and 3. All authors have read and agreed to the published version of the manuscript.

Funding: This research received no external funding.

Institutional Review Board Statement: Not applicable.

Informed Consent Statement: Not applicable.

Data Availability Statement: Data available in a publicly accessible repository that does not issue DOIs. Publicly available datasets were analyzed in this study. This data can be found here: [http: //sedici.unlp.edu.ar/handle/10915/73059, accessed on 21 November 2018]; [http://sedici.unlp.edu. ar/bitstream/handle/10915/92156/Documento_completo.pdf?sequence=1\&isAllowed=y, accessed on 11 October 2019]. 
Acknowledgments: We would like to thank the National Scientific and Technical Research Council (CONICET) for the funding provided through a Type I PhD Scholarship granted to Gabriel Alberto Ramírez Díaz, Engineer. We would also like to thank the Comisión de Investigaciones Científicas (CIC) [Scientific Research Council] of the Province of Buenos Aires for the funding provided through a PhD Scholarship to Lucas Sznajderman No. 2018-207-GDEBA-CICMCTI.

Conflicts of Interest: We consider that the manuscript conforms to the journal since it addresses issues of interest related to air transport and its relationship with certain environmental aspects. In this context jointly covers aspects of planning, design and operation of infrastructure, and its relationship with the environment.

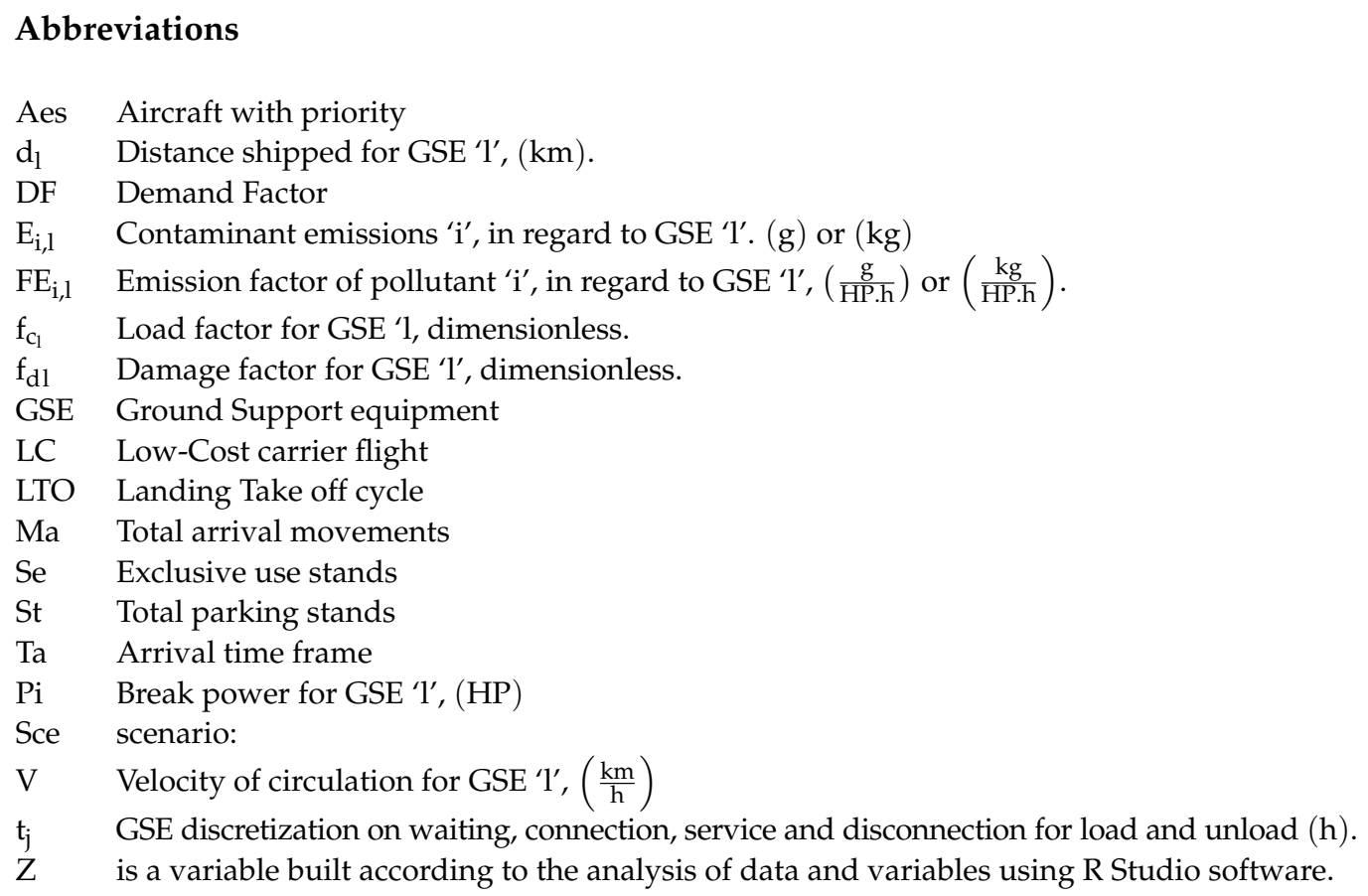

\section{Appendix A. Conflict Resolution Rules}

Figure A1, where you can see the evaluation of the benefits resulting from using a secondary taxiway or waiting for the primary taxiway to be free. The alternative minimizing the waiting times shall be chosen. If the assigned gate is taken, an alternative one shall be assigned, and the decision-making process, repeated.

As it can be observed in Figure A2, in case of conflicts during the taxiway, priority is given to the departing aircraft in order to free the congestion level on the apron. In case of delays in the departure queue, aircraft accommodate the delay in the gate, as long as there are free stands. 

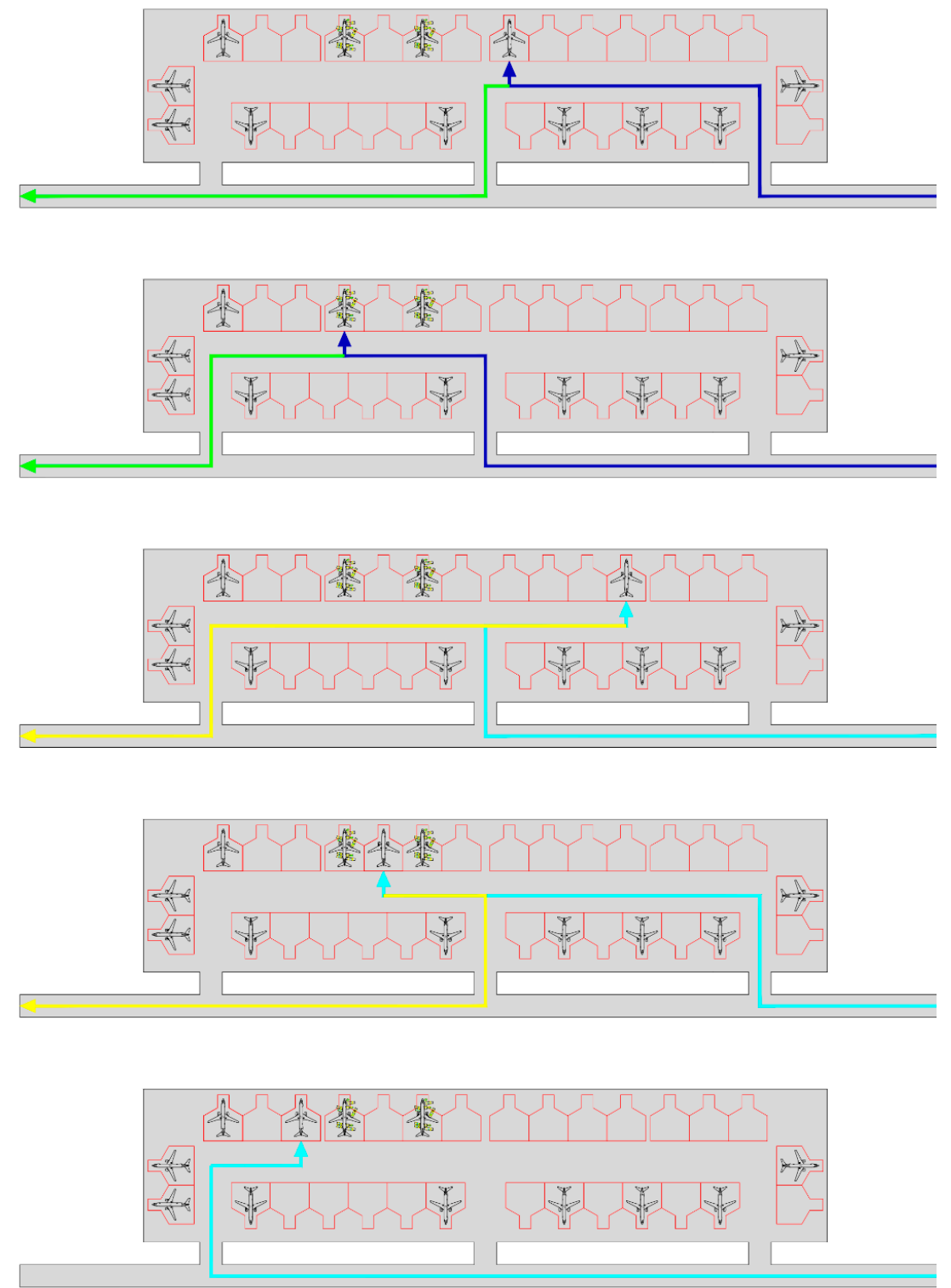

Figure A1. Apron diagram, main traffic direction.

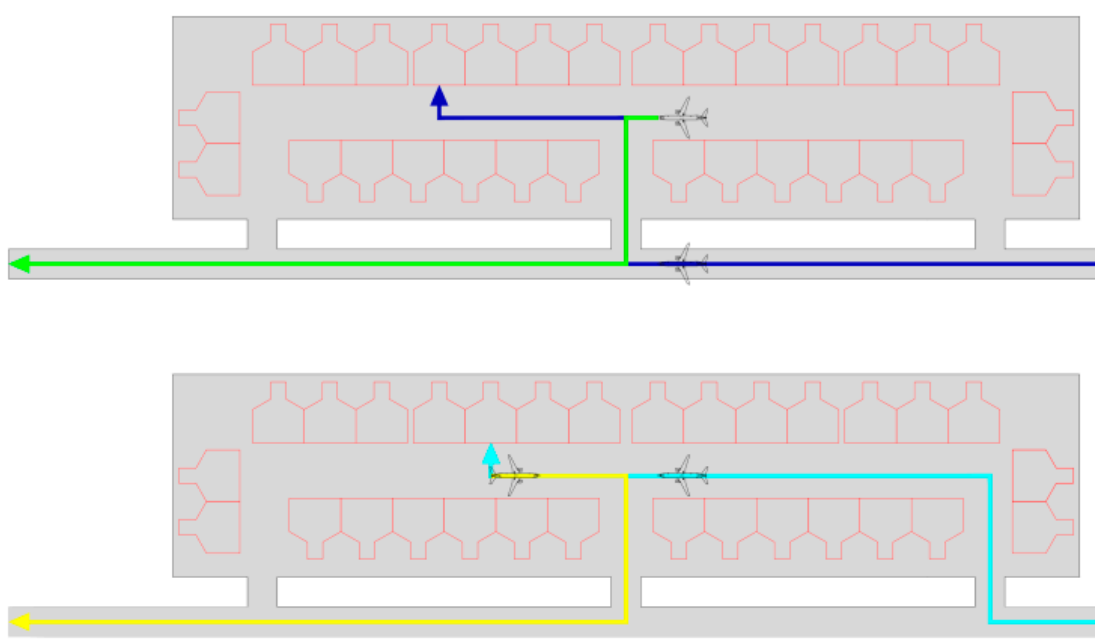

Figure A2. Taxiway conflicts. 


\section{Appendix B. Characterization of Processes-Probability Distributions}

Turnaround process

Figure A3 summarizes that pattern, in which, for instance, it can be observed that approximately $40 \%$ of the aircraft show a turnaround time lower than $70 \mathrm{~min}$.

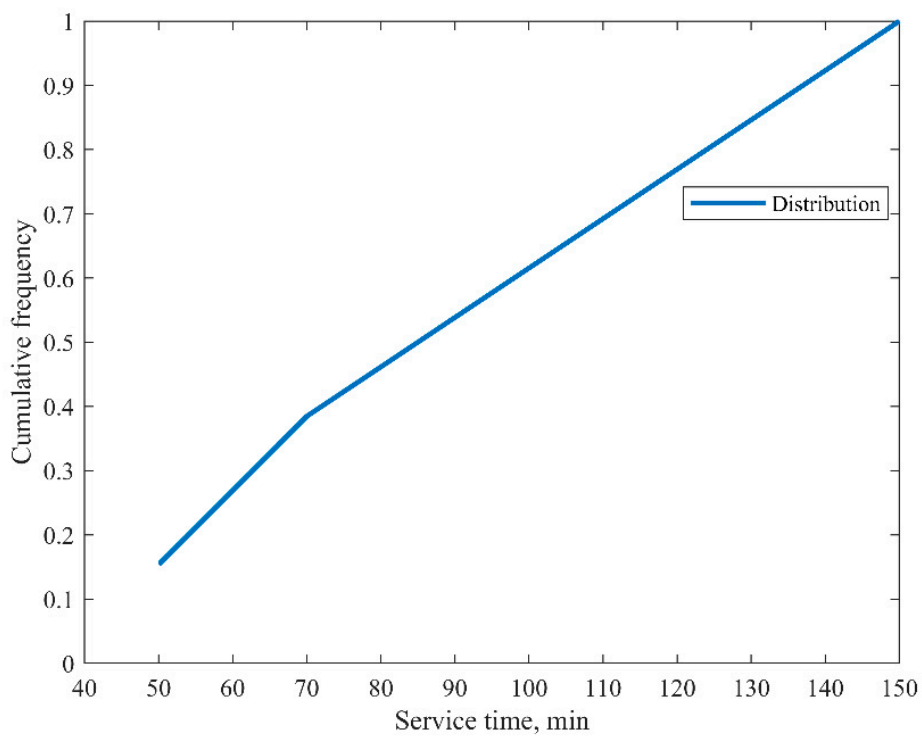

Figure A3. Service time distribution of the turnaround process.

Arrival latency and departure latency

Probability distributions produce randomness that have an impact on the scheduled hours of the execution process, which, in turn, affect system capacity and performance. In this study, the processes of arrival latency, departure latency, and pushback have been characterized using the cumulative frequency distributions of Figures A4-A7.

The arrival latency was modelled by the distribution shown in Figure A4, even though the behavior of this variable was significantly distinct from one airport to the other. The latency distribution is adapted from [22], given that our aim was to add randomness to the process.

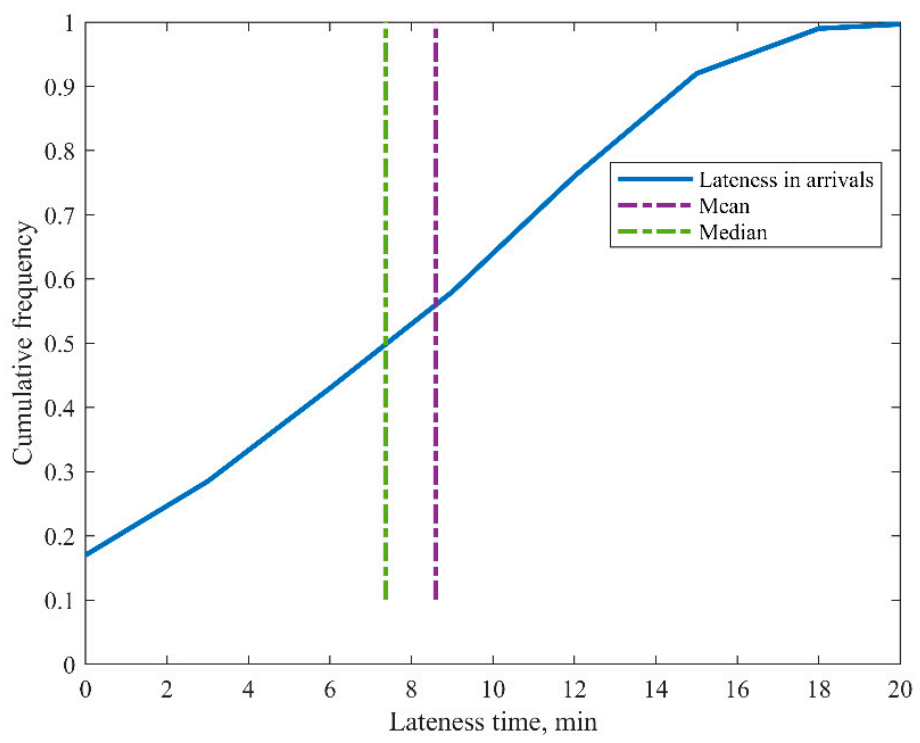

Figure A4. Arrival latency distribution. 
On the other hand, when considering the scheduled hours for departure flights, a departure latency probability was included ranging from 0 to $20 \mathrm{~min}$ with the distribution law observed on Figure A5 based on usual delays that might be produced by processes in the terminal or delays in apron services managed as buffer times.

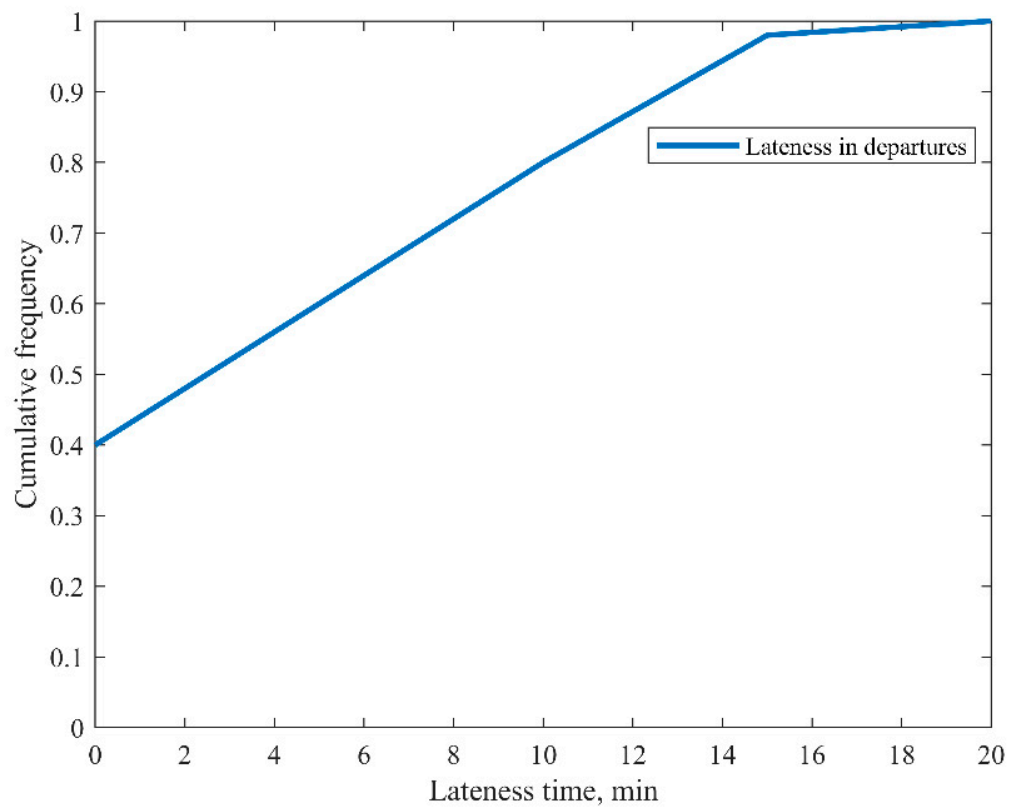

Figure A5. Departure latency distribution.

\section{Pushback process}

The pushback process is divided into two operations. The first one is the towing of aircraft from gate to taxiway line (Figure A6), and the second one is the start-up of the aircraft (Figure A7). Both processes were modelled according to established probability distributions [23]. Later, pushback process was sampled for SABE, with the sampling results compatible with the distribution used.

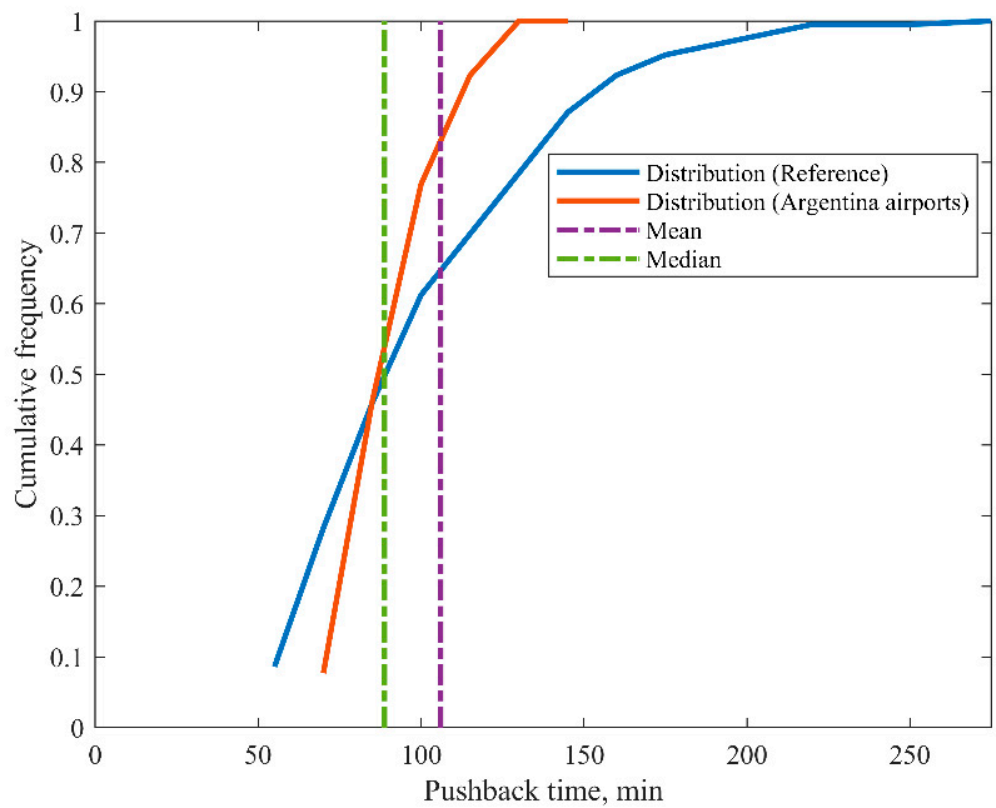

Figure A6. Characterization of pushback time process [24]. 


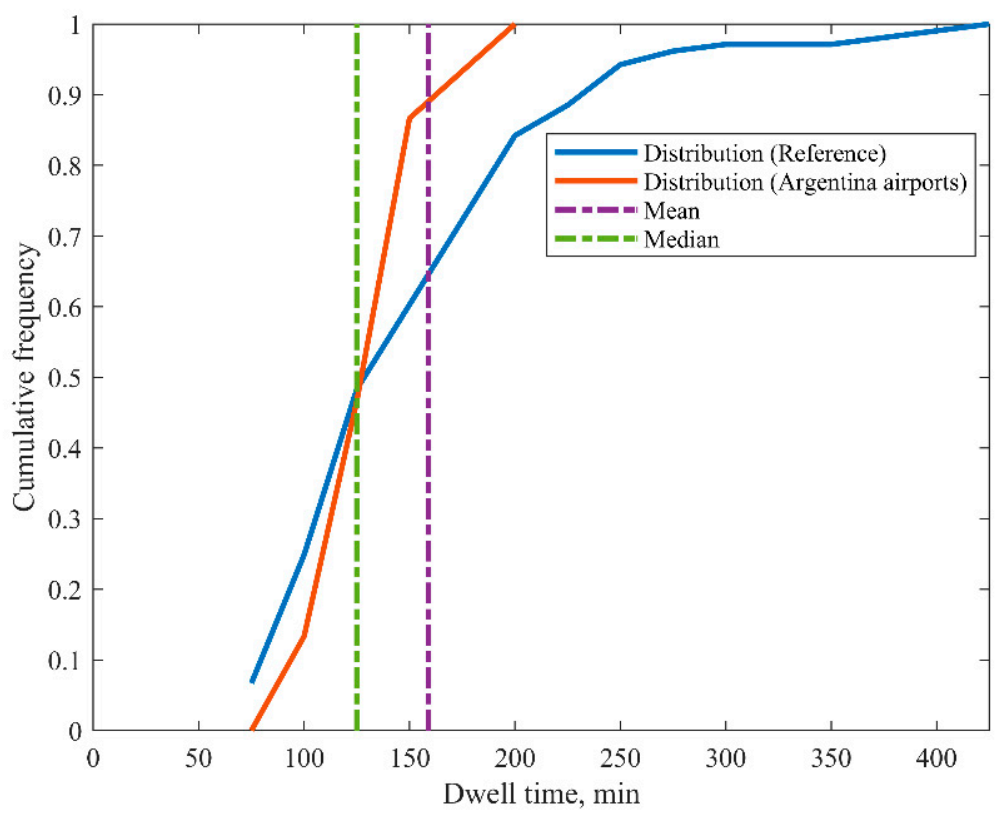

Figure A7. Characterization of dwell time process.

\section{Appendix C. GSE Factor}

Maximum power, loading, or power factor

Based on the field data gathering, the proposed model times have been measured, and GSE models have been characterized in order to relate their power plant and observe the engine state in the service to estimate loading factors.

Next, maximum powers and load factors used in the model are presented in Tables A1-A3:

Table A1. Maximum powers studied from observed GSE models and load factors in traffic.

\begin{tabular}{cccc}
\hline Code GSE & GSE & Power [HP] & Load Factor \\
\hline BT & Baggage tractor & 88 & 0.475 \\
BL & Belt loader & 88 & 0.350 \\
TUG & TUG & 134 & 0.375 \\
BUS & Bus & 177 & 0.363 \\
R. BUS & Bus for passengers with reduced mobility & 330 & 0.283 \\
CAT & Catering & 330 & 0.490 \\
LV & Vacuum toilet & 75 & 0.283 \\
WP & Water potable & 235 & 0.263 \\
CLE & Cleaning & - & 0.350 \\
GPU & Ground Power Unit & 187 & 0.475 \\
PS & Passenger stairs & 88 & 0.475 \\
FUEL & Fuel truck & 320 & 0.388 \\
\hline
\end{tabular}

Loading factors are those components affecting the maximum power, obtained from the software Aviation Environmental Design Tool (AEDT 2d), and adjusted depending on the field study. Hereafter, values adopted for the model according to the traffic process in apron and also for luggage and goods loading and unloading, and passenger movement can be observed. The importance of such factors has increased due to the characteristic curves of power-RPM according to the mechanization of each vehicle for every operational status. 
Table A2. Load factors according to loading times and operation.

\begin{tabular}{ccccc}
\hline \multirow{2}{*}{ GSE } & \multicolumn{4}{c}{ Load Factors } \\
\cline { 2 - 5 } & Waiting & Connection & Service & Disconnection \\
\hline Baggage tractor & 0.36 & 0.36 & 0.55 & 0.36 \\
Belt loader & 0.36 & 0.36 & 0 & 0.36 \\
TUG & 0.40 & 0.40 & 0.80 & 0.40 \\
Bus & 0.20 & 0 & 0.20 & 0 \\
R. Bus & 0.20 & 0 & 0.20 & 0 \\
Catering & 0.53 & 0.53 & 0 & 0.53 \\
Lavatory & 0.25 & 0.25 & 0.25 & 0.25 \\
Water potable & 0.20 & 0.20 & 0.20 & 0.20 \\
Cleaning & 0.33 & 0 & 0 & 0 \\
Ground Power Unit & 0 & 0 & 0.8 & 0 \\
Passenger stairs & 0.57 & 0 & 0 & 0 \\
Fuel truck & 0 & 0.25 & 1 & 0.25 \\
\hline
\end{tabular}

Table A3. Load factors according to unloading times and operation.

\begin{tabular}{ccccc}
\hline \multirow{2}{*}{ GSE } & \multicolumn{4}{c}{ Load Factors } \\
\cline { 2 - 5 } & Waiting & Connection & Service & Disconnection \\
\hline Baggage tractor & 0.36 & 0.36 & 0.55 & 0.36 \\
Belt loader & 0.36 & 0.36 & 0 & 0.36 \\
TUG & 0 & 0 & 0 & 0 \\
Bus & 0.20 & 0 & 0.20 & 0 \\
R. Bus & 0.20 & 0 & 0.20 & 0 \\
Catering & 0.53 & 0.53 & 0 & 0.53 \\
Lavatory & 0.25 & 0.25 & 0 & 0.25 \\
Water potable & 0.20 & 0.20 & 0 & 0.20 \\
Cleaning & 0.33 & 0 & 0 & 0 \\
Ground Power Unit & 0 & 0 & 0 & 0 \\
Passenger stairs & 0.57 & 0 & 0 & 0 \\
Fuel truck & 0 & 0.25 & 1 & 0.25 \\
\hline
\end{tabular}

Emission factor

Emission factors are obtained from the same database than loading factors. In order to obtain them, tests are performed on engines with no operating hours, at maximum power and according to the type of fuel. Next, Table A4 shows the emission factors according to the pollutant gas for used GSE.

Table A4. Emission factor according to GSE type of vehicle.

\begin{tabular}{ccc}
\hline GSE & $\begin{array}{c}\mathbf{C O}^{\prime} \mathbf{i}^{\prime} \\
(\mathbf{g} / \mathbf{H P . h})\end{array}$ & $\begin{array}{c}\mathbf{N O}_{\mathbf{x}} \mathbf{~} \mathbf{}^{\prime} \\
\text { (g/HP.h) }\end{array}$ \\
\hline Baggage tractor & 1.503 & 4.485 \\
Belt loader & 2.553 & 4.544 \\
TUG & 1.503 & 4.485 \\
Bus & 0.110 & 2.500 \\
Catering & 0.449 & 1.037 \\
Vacuum toilet & 0.654 & 2.417 \\
Water potable & 0.804 & 2.898 \\
Ground Power Unit & 0.961 & 4.135 \\
Passenger stairs & 0.801 & 2.891 \\
Fuel truck & 0.614 & 2.184 \\
\hline
\end{tabular}


Damages factor

The damages factor enlarges the value of emissions produced by the years of use. Particularly, software EDMS V.5.0 proposes Equation (A1).

$$
f_{d}=1+A\left(\frac{G S E_{\text {year }}}{G S E_{\text {lifetime }}}\right)^{b}
$$

For each gaseous pollutant in the study, there are two types of auxiliary coefficients for damages measurement, according to the corresponding power range. Such coefficients were updated to 2010, the proposed year for the study. Therefore, it is presumed by default that the equipment has been used for nine years. The damages factor also depends on the year of service and the average lifetime of the GSE equipment. The following values are then deduced for all analyzed vehicles: for $\mathrm{CO}$, coefficients $A$ and $b$ are 0.150 and 1 respectively, whereas for NOx, $A$ and $b$ are 0.008 and 1 , respectively.

From the corresponding coefficients, together with the years of service and lifetime of each equipment, damages factors are obtained, as shown in Table A5.

Table A5. Service years and lifetime per GSE type of vehicle for the damages factor. Service times.

\begin{tabular}{ccccc}
\hline GSE & Use (Years) & Lifespan (Years) & CO & NOx \\
\hline Baggage tractor & 8 & 13 & 1.092 & 1.005 \\
Belt loader & 8 & 11 & 1.092 & 1.005 \\
TUG & 8 & 14 & 1.086 & 1.005 \\
Bus & 8 & 10 & 1.100 & 1.005 \\
R. Bus & 8 & 10 & 1.100 & 1.006 \\
Catering & 8 & 10 & 1120 & 1.006 \\
Vacuum toilet & 8 & 13 & 1.120 & 1.006 \\
Water potable & 8 & 10 & 1.120 & 1.006 \\
Ground Power Unit & 8 & 14 & 1.120 & 1.006 \\
Passenger stairs & 8 & 14 & 1.120 & 1.006 \\
Fuel truck & 8 & 14 & 1.086 & 1.005 \\
\hline
\end{tabular}

\section{References}

1. Wing, A.K.; Felder, W.N.; Cloutier, R.J. Modeling a Ramp Area Support System. In Proceedings of the 15th AIAA Aviation Technology, Integration, and Operations Conference, Dallas, TX, USA, $22-26$ June 2015; American Institute of Aeronautics and Astronautics: Reston, VA, USA, 2015. [CrossRef]

2. Schmidt, M.; Paul, A.; Cole, M.; Ploetner, K.O. Challenges for ground operations arising from aircraft concepts using alternative energy. J. Air Transp. Manag. 2016, 56, 107-117. [CrossRef]

3. Palocz-Andresen, M. Emissions at airports and their impact at the habitat. Period. Polytech. Mech. Eng. 2009, 53, 13. [CrossRef]

4. Hannah, J.; Hettmann, D.; Rashid, N.; Saleh, C.; Yilmaz, C. Design of a carbon neutral airport. In Proceedings of the 2012 IEEE Systems and Information Engineering Design Symposium, Institute of Electrical and Electronics Engineers (IEEE), Charlottesville, VA, USA, 27-27 April 2012; pp. 40-45. [CrossRef]

5. Winther, M.; Kousgaard, U.; Ellermann, T.; Massling, A.; Nøjgaard, J.K.; Ketzel, M. Emissions of NOx, particle mass and particle numbers from aircraft main engines, APU's and handling equipment at Copenhagen Airport. Atmos. Environ. 2015, 100, 218-299. [CrossRef]

6. Airport Air Quality Manual Doc 9889; International Civil Aviation Organization (ICAO): Montreal, QC, Canada, 2011; Volume 1.

7. Mirkovic, B.; Tošić, V. Airport apron capacity: Estimation, representation, and flexibility. J. Adv. Transp. 2013, 48, 97-118. [CrossRef]

8. Mirković, B.; Tošić, V. The difference between hub and non-hub airports-An airside capacity perspective. J. Air Transp. Manag. 2017, 62, 121-128. [CrossRef]

9. Deng, W.; Sun, M.; Zhao, H.; Li, B.; Wang, C. Study on an airport gate assignment method based on improved ACO algorithm. Kybernetes 2018, 47, 20-43. [CrossRef]

10. Guclu, O.E.; Cetek, C. Analysis of aircraft ground traffic flow and gate utilisation using a hybrid dynamic gate and taxiway assignment algorithm. Aeronaut. J. 2017, 121, 721-745. [CrossRef]

11. Kim, S.H.; Feron, E.; Clarke, J.-P. Assigning gates by resolving physical conflicts. In Proceedings of the AIAA Guidance, Navigation, and Control Conference, Chicago, IL, USA, 10-13 August 2009; p. 16. [CrossRef] 
12. Carpenter, M.; Stroiney, S. Managing gate and ramp operations to reduce delay, fuel burn, and costs. In Proceedings of the 2012 Integrated Communications, Navigation and Surveillance Conference, Herndon, VA, USA, 24-26 April 2012. [CrossRef]

13. Kuzu, S.L. Estimation and dispersion modeling of landing and take-off (LTO) cycle emissions from Atatürk International Airport. Air Qual. Atmos. Health 2017, 11, 153-161. [CrossRef]

14. Janić, M. Analyzing, modeling, and assessing the performances of land use by airports. Int. J. Sustain. Transp. 2015, 10, 683-702. [CrossRef]

15. Mota, M.M.; Boosten, G.; De Bock, N.; Jimenez, E.; de Sousa, J.P. Simulation-based turnaround evaluation for Lelystad Airport. J. Air Transp. Manag. 2017, 64, 21-32. [CrossRef]

16. Mota, M.; Di Bernardi, A.; Scala, P.; Ramirez-diaz, G. Simulation-based virtual cycle for multi-level airport analysis. Aerosp. Sci. Technol. 2018, 5, 44. [CrossRef]

17. Ferrulli, P. Green airport design evaluation (GrADE)—Methods and tools improving infrastructure planning. Transp. Res. Procedia 2016, 14, 3781-3790. [CrossRef]

18. Challenges of Growth 2013-Task 4: European Air Traffic in 2035; Eurocontrol: Brussels, Belgium, 2013.

19. Yilmaz, I. Emissions from passenger aircraft at Kayseri Airport, Turkey. J. Air Transp. Manag. 2017, 58, 176-182. [CrossRef]

20. Edb-Emissions-Databank v25a (web); International Civil Aviation Organization (ICAO): Montreal, QC, Canada, 2018.

21. Tan, Y.L. Differences in Ground Handling in the Global Market Yik Lun Tan; Project of Hamburg University of Applied Sciences: Hambourg, Germany, 2010; pp. 1-34.

22. Fleuti, E. Aircraft Ground Handling Emissions; Zurich Airport: Flughafen Zürich, Switzerland, 2014; p. 20.

23. Wu, C.; Caves, R.E. Modelling and optimization of aircraft turnaround time at an airport. Transp. Plan. Technol. 2004, 27, 47-66. [CrossRef]

24. Coupe, J.; Milutinovic, D.; Malik, W.; Jung, Y.C. A Data Driven Approach for Characterization of Ramp Area Push Back and Ramp-Taxi Processes. In Proceedings of the 16th AIAA Aviation Technology, Integration, and Operations Conference, Washington, DC, USA, 13-17 June 2016; pp. 1-15. [CrossRef] 